\title{
Endoscopic Assisted Microscopic Surgical Removal of Craniopharyngioma
}

\author{
Waleed Abbass, Amr Mohsen \\ Department of Neurosurgery, Faculty of Medicine, Cairo University, Giza, Egypt \\ Email:waleed.abbass@yahoo.com
}

How to cite this paper: Abbass, W. and Mohsen, A. (2020) Endoscopic Assisted Microscopic Surgical Removal of Craniopharyngioma. Open Journal of Modern Neurosurgery, 10, 475-482.

https://doi.org/10.4236/ojmn.2020.104048

Received: April 4, 2020

Accepted: October 26, 2020

Published: October 29, 2020

Copyright (อ 2020 by author(s) and Scientific Research Publishing Inc. This work is licensed under the Creative Commons Attribution International License (CC BY 4.0).

http://creativecommons.org/licenses/by/4.0/ (c) (i) Open Access

\begin{abstract}
Background: Craniopharyngioma is a benign tumor which represents $2 \%$ $3 \%$ of all intracranial tumors, there are two types: childhood type which affects children between 5 and 10 years and adulthood type which affects patients 50 - 60 years old. The presenting symptoms develop over years and include visual, endocrine, hypothalamic, neurological and neurophysiological manifestations. Surgery is the treatment of choice. Postoperative radiotherapy, gamma-knife and intra tumoral injection of chemotherapeutic drugs have been used as an adjuvant therapy in some cases. Objectives: In this study, we evaluated the role of endoscopy in assisting microscopic surgical removal of craniopharyngioma. Methods: Eleven patients were operated upon in Cairo University Hospitals, Egypt. All operations were done using microscope through the subfrontal approach. At the end of surgery, the endoscope was used to detect any residual tumor in the subchiasmatic and retrochiasmatic areas and to visualize the posterior part of the tumor which couldn't be seen by the microscope to check if it was adherent to the hypothalamus and to evaluate whether to be removed or not. Results: The study included eleven cases, four of which were childhood type and seven adult type craniopharyngiomas. Total removal was achieved in six cases (five cases of adulthood type). Oumaya reservoir was inserted in five cases; ventriculoperitoneal shunt was needed in five cases. All cases suffered from temporary diabetes insipidus postoperatively, while only two cases developed permanent diabetes insipidus. Three cases presented preoperatively with pituitary hypofunction and two cases developed postoperative pituitary hypofunction, which necessitated hormone replacement therapy. Conclusion: Craniopharyngioma is one of the most difficult and challenging tumors for neurosurgeons due to its relation to optic nerve, hypothalamus and vascular system formed by Willis circle and its perforating branches. Endoscopy has a role in decision making after microscopic removal of craniopharyngioma.
\end{abstract}




\section{Keywords}

Craniopharyngiomas, Endoscopy, Microscopy, Surgery

\section{Introduction}

Craniopharyngiomas occur at a rate of 1.3 per million person years. There are two age groups for craniopharyngioma which are the childhood type and adulthood type [1]. Despite being located in a very critical area related to the hypothalamus and neurovascular structures, it is a benign tumor in which every attempt must be done to achieve total resection [2].

Several approaches have been used for the resection of craniopharyngiomas such as subfrontal, interhemispheric, pterional, transcallosal transventricular and transsphenoid approach with its different modifications either extended transsellar transdipharagmatic approach or transsphenoid transtuberculum sellae approach, however, the rate of cerebrospinal fluid leakage is mach much more in transsphenoid than transcranial surgeries. The limitation of transsphenoid approach is the lateral extension of the tumour or if there is enchasing of vascular structures [3] [4] [5].

As this tumour is closely related to the optic nerves, chiasm and hypothalamus, total removal cannot be achieved without difficulty. The anatomic difficulties in total resection are usually encountered at the level of the hypothalamicpituitary complex, the optic nerves and the chiasm, where the resection may become limited. Microsurgery undisputedly improves the tumor bulk removal, it has been reported that total resection could be achieved in up to $75 \%$ of cases. Adding endoscopy to the microsurgical instrumentation has improved the total resection rate by nearly $10 \%$ [1] [6].

Several modalities have been used for the treatment of craniopharyngioma either surgery alone or surgery with insertion of oumya reservoir (if the cystic part cannot be removed) or surgery followed by radiotherapy or gamma knife. With the development of technology and introduction of new instruments as neuronavigation and endoscopes, better results have been achieved regarding the amount of resection and the quality of life [7].

\section{Aim of the Work}

We aim in this paper to study the possibility of achieving a higher rate of resection by using an additional instrument, the endoscope.

\subsection{Clinical Picture}

Visual compromise and endocrine deficiency prevail among presenting symptoms, followed by symptoms due to hydrocephalus. Growth delay is a typical finding in children harboring craniopharyngiomas [4]. 


\subsection{Diagnosis and Investigations}

Diagnosis of craniopharyngioma is usually made by magnetic resonance imaging (MRI) [8]. If MRI is suggestive of a craniopharyngioma, a computerized tomography $(\mathrm{CT})$ is additionally performed to detect calcifications, since craniopharyngiomas typically show the trias of calcified, solid and cystic tumor portions. Endocrine and ophthalmological examinations are mandatory for preoperative work-up.

\section{Patients \& Methods}

This is a retrospective study which included eleven patients suffering from craniopharyngiomas as diagnosed preoperatively by radiological investigations and confirmed by postoperative histological analysis. All these cases were admitted to our Department of Neurosurgery, Cairo University and underwent an endoscopy assisted microsurgical resection of their tumors between January 2015 and January 2017.

All these tumors had solid and cystic components, full neurological examination and full lab investigations were done. MRI, visual and endocrine examinations were done before and after surgery (Figure 1 \& Figure 2). MRI was performed postoperatively and repeated at 3 months, 6 month, then annually. During the follow-up period which extended between 6 months to one year. All these tumors were removed by a subfrontal approach. Our technique is based on performing a small right frontal flap, a linear opening of the dura parallel to the skull base, then smooth retraction of the frontal lobe, opening of basal cisterns, and decompressing the brain by puncturing the tumor cyst and removing the bulky part of the tumor by gentle traction. The lamina terminalis is opened in the case of a retrochiasmatic location of the tumor. The decompression is usually performed using the microsurgical technique until we judge that no more resection is possible without risk.

At this point in the surgery we introduce the rigid endoscope $0^{\circ}, 30^{\circ}$ and $70^{\circ}$ with endoscopic microforceps, micro dissectors and bipolar coagulation. During surgical removal, all the three different angled endoscopes are used to explore the tumor site. The $30^{\circ}$ and $70^{\circ}$ scopes were used to explore the inferior surface of the optic nerves and the superior-posterior limit of the tumor stuck to the hypothalamus. The $30^{\circ}$ endoscope is usually used to remove the remainder of the tumor at these two levels by dissection and gentle traction using micro dissectors and endoscopic forceps.

Although the $70^{\circ}$ endoscope gives an odd picture for dissection, it is usually used to verify the total resection. At the end of the procedure several endoscopes with different angles are used to make sure that total resection had been achieved.

\section{Results}

This study included eleven patients all operated by Subfrontal approach with in- 
troduction of endoscope at the end of the operation for the assessment of tumor removal and dissection of remaining parts if feasible. The results were four cases of childhood variant of craniopharyngioma and the remaining were of the adult type six patients were males and five were females total removal was achieved in six cases five of them of the adulthood type.

Subtotal resection was achieved in five patients due to adherence to the hypothalamus and perforating vessels, three of received postoperative radiotherapy.
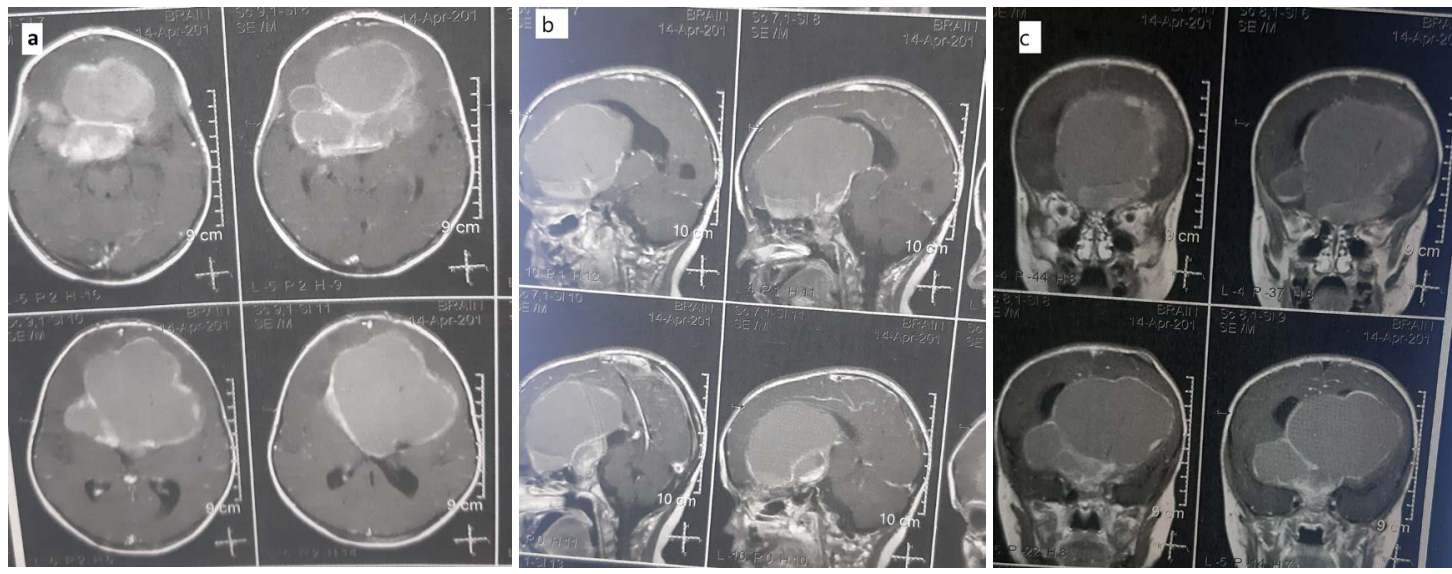

Figure 1. Preoperative axial (a), sagittal (b) and coronal (c) MRI showing huge sellar suprasellar craniopharyngioma.

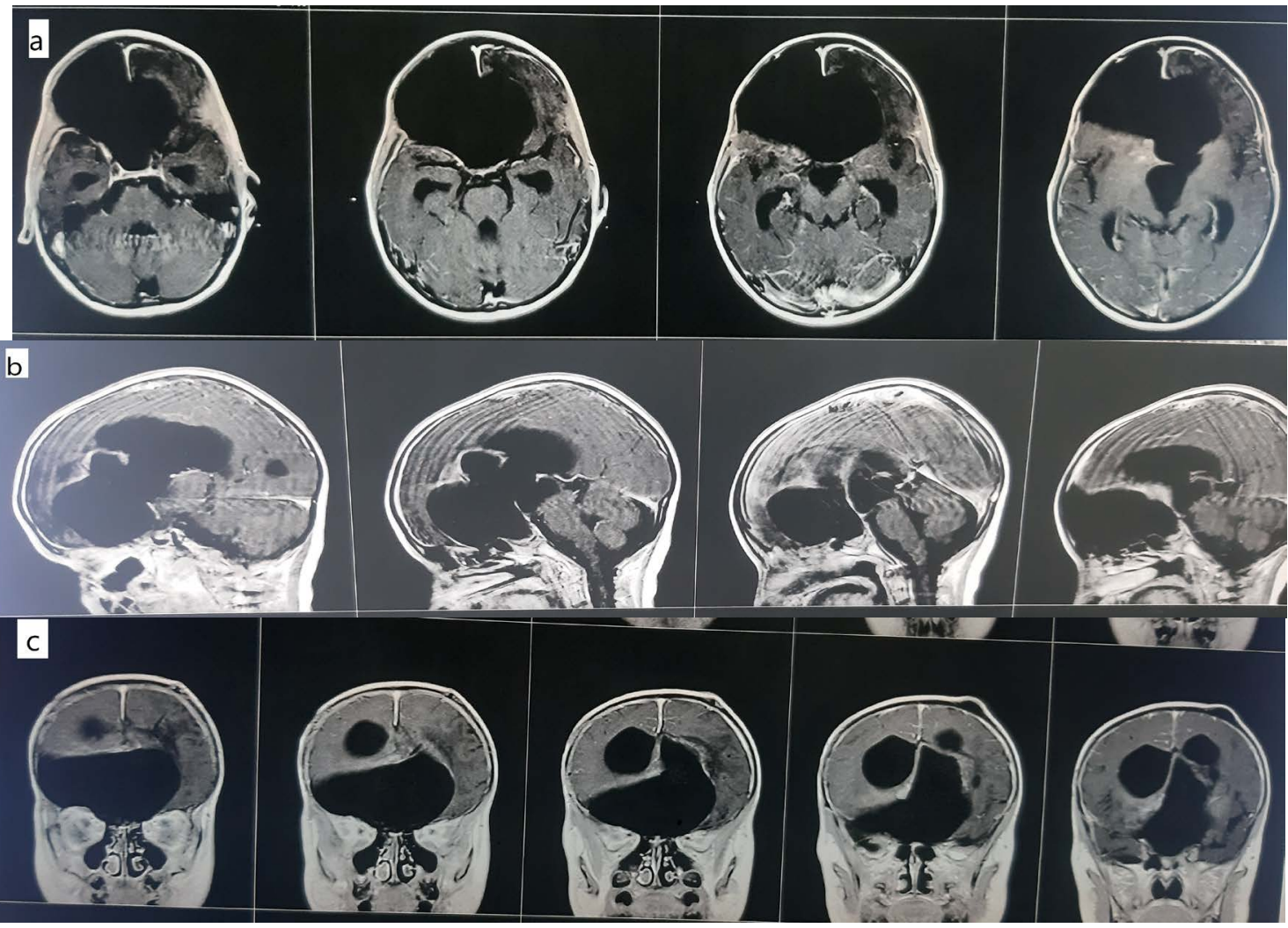

Figure 2. Postoperative axial (a), sagittal (b) and coronal (c) MRI showing complete removal of the tumor (6 months after surgery). 
Oumyea reservoir was inserted in five cases as the cystic part could not be removed. V-P shunt was inserted in five cases. All the patients developed diabetes insipidus (DI) after surgery only two of which were permanent DI. Two cases preoperatively were suffering from pituitary hypofunction after surgery they became three.

The visual field was affected in all patients, it improved after surgery in two patients and worsened in two others. No deterioration of the visual acuity was noted using this technique. There were two postoperative mortalities one patient died from uncontrolled hypernatremia, and one other died from sequelae of intraoperative hemorrhage.

\section{Discussion}

Craniopharyngioma is a benign tumor that is located at the base of the skull and represents nearly $14 \%$ of the CNS tumor [9]. Because of the anatomic complexity of this location and the surrounding structures that could potentially cause endocrine, autonomic, and behavioral problems, the total resection of the craniopharyngioma is a major challenge for neurosurgeons [10].

As early as 1969, Matson and Crigler concluded from their experience with childhood craniopharyngiomas that the rate of recurrence is much more in patients with partial or subtotal resection and that every attempt must be done to achieve total resection in the first operation [3].

Total surgical resection of craniopharyngioma must be the aim of the surgeon as the rate of recurrence and survival rate is related to the amount of resection, but it most not come on the expense of quality of life such as subsequent hypothalamic manifestations [11].

There are certain limitations that must be considered preoperatively such as obesity in children, which may be a predictor to severe hypothalamic disorder postoperatively, also elderly patients with morbidities.

There is controversy regarding partial or subtotal removal of craniopharyngioma followed by radiotherapy. The Pittsburgh group have a rate of $89.1 \%$ control of the tumor after subtotal removal and radiotherapy after 10-years follow-up [12].

The Oxford series had no recurrence in the tumors totally resected followed by radiotherapy.

One of the limitations of total resection is the adherence of the tumor to the hypothalamus. If the tumor is not suckable, attempts should not be done to remove it by grasping to avoid severe hypothalamic affection. The other limitation is the adherence of the tumor to the vessels and perforators with no plane of cleavage between them [13].

Fischer reported a total resection rate of $27 \%$ of all patients in his series [14].

This rate is much higher according to other authors where it varies from $60 \%$ to $76 \%$ depending on the surgical experience and the used techniques.

In the study performed by Yasargil et al. in 1990 which included 144 patients from which 51 were adults (35.1\%), he used the pterional approach with $90 \%$ 
total removal rate and mortality $9 \%$ and $7 \%$ rate of recurrence without the use of radiotherapy [15].

In the study done by Fahlbusch et al. in 1999 which included 168 cases from which 80 were adults $(47.6 \%)$ he used three approach, mainly pterional then transsphenoid and then the bifrontal approach. Total removal was achieved in $(49 \%)$ in primary tumors only, mortality occured in $0.7 \%$ in primary tumors and $10 \%$ in recurrent tumors with a rate of recurrence of $11 \%$ without the use of radiotherapy [13].

In the study done by Di Rocci et al. in 2006 which included 54 cases of childhood type craniopharyngiomas using the pterional approach, total removal was achieved in $78 \%$, mortality rate was $3.7 \%$ and the rate of recurrence was $7 \%$ [7].

In the study done by Shi et al. in 2006 which included 284 patients from which 80 patients are adults $(28.1 \%)$ using both the pterionelal and the bifrontal approach but mainly the pterional approach. Total removal was achieved in $84 \%$, mortality was $4.2 \%$ and the rate of recurrence was $14 \%$ [16].

In a former group of 69 patients under the age of 17 years operated on for a craniopharyngioma in the study of H. Kadri and A.A. Mawlade [1] by the microsurgical technique alone a total resection rate of $62.4 \%$. In this current group we operated on eleven cases suffering from craniopharyngioma by microsurgical techniques assisted by endoscopy, eight out of eleven patients (72.3\%) had a total resection that means that we improved the total resection rate by nearly $10 \%$ after adding the endoscope to the instrumentation.

Although these rates are considered to be not statistically significant ( $\mathrm{p}>$ 0.05 ), we found that this technique improves and facilitates the total removal of the tumor in a safe manner despite the fact that the radical removal of these tumors has a higher rate of complications, it provides the best outcome.

Complications are usually related to the large volume of the tumor and in the majority of cases they are of either a hormonal and/or a visual nature such complications are related to the complex anatomic relationship between tumor, the visual track and the hypothalamus. No significant differences in the incidence of hormonal and/or visual complications were observed between our group of patients and the former group.

Using our technique, the visual field was improved in two patients after tumor debulking while it was aggravated in two others. Meanwhile diabetes insipidus has occurred in all patients after surgery and became permanent in only two patients. The incidence of recurrence after total resection is reported to be $11 \%-31 \%$.

Partial resection carries a higher rate of recurrence, which varies from $22 \%$ up to $100 \%$ according to many authors. Our mortality rate was $7 \%$ (two patients: one died from uncontrolled hypernatriemia, and one patient died as a long-term result of an incidental intraoperative hemorrhage.

\section{Conclusion}

Total resection remains the best surgical treatment of craniopharyngioma. In 
our experience, endoscopy seems to improve the microsurgical removal of the craniopharyngioma without additional complications.

\section{Conflicts of Interest}

The authors declare no conflicts of interest regarding the publication of this paper.

\section{References}

[1] Kadri, H. and Mawlade, A.A. (2005) Incidence of Childhood Brain Tumor in Syria. Pediatric Neurosurgery, 41, 173-177. https://doi.org/10.1159/000086557

[2] Aryan, H.E., Ozgur, B.M., Jandial, R. and Levy, M.L. (2005) Subfrontal Transbasal Approach and Technique for Resection of Craniopharyngioma. Neurosurgical Focus, 18, E10. https://doi.org/10.3171/foc.2005.18.6.11

[3] Kaptain, G.J., Vincent, D.A., Sheehan, J.P. and Laws, E.R. (2001) Transsphenoidal Approaches for the Extracapsular Resection of Midline Suprasellar and Anterior Cranial Base Lesions. Neurosurgery, 49, 94-101. https://doi.org/10.1227/00006123-200107000-00014

[4] Samii, M. and Tatagiba, M. (2000) Surgery of Craniopharyngiomas. In: Kaye, A.H. and Black, P.M., Eds., Operative Neurosurgery, Churchill Livingstone, London, 741 749 .

[5] Yasargil, M.G., Curcic, M., Kis, M., Siegenthaler, G., Teddy, P.J. and Roth, P. (1990) Total Removal of Craniopharyngiomas. Journal of Neurosurgery, 73, 3-11. https://doi.org/10.3171/jns.1990.73.1.0003

[6] Liu, J.K., Cole, C.D., Kestle, J.R., Brockmeyer, D.L. and Walker, M.L. (2005) Cranial Base Strategies for Resection of Craniopharyngioma in Children. Neurosurgical Focus, 18, E9. https://doi.org/10.3171/foc.2005.18.6.10

[7] Di Rocco, C., Caldarelli, M., Tamburrini, G. and Massimi, L. (2006) Surgical Management of Craniopharyngiomas-Experience with a Pediatric Series. Journal of Pediatric Endocrinology and Metabolism, 19, 355-366.

[8] Van Effenterre, R. and Boch, A.L. (2002) Craniopharyngioma in Adults and Children: A Study of 122 Surgical Cases. Journal of Neurosurgery, 97, 3-11. https://doi.org/10.3171/jns.2002.97.1.0003

[9] Muller, H.L., Faldum, A., Etavard-Gorris, N., et al. (2003) Functional Capacity, Obesity and Hypothalamic Involvement: Cross Sectional Study on 212 Patients with Childhood Craniopharyngioma. Klinische Pädiatrie, 215, 310-314.

https://doi.org/10.1055/s-2003-45499

[10] Chakrabarti, I., Amar, A.P., Couldwell, W. and Weiss, M.H. (2005) Long-Term Neurological, Visual and Endocrine Outcome Following Pituitary Transnasal Resection of Craniopharyngioma. Journal of Neurosurgery, 102, 650-657. https://doi.org/10.3171/jns.2005.102.4.0650

[11] De Vile, C.J., Grant, D.B., Kendall, B.E., et al. (1996) Management of Childhood Craniopharyngioma: Can the Morbidity of Radical Surgery Be Predicted? Journal of Neurosurgery, 85, 73-81. https://doi.org/10.3171/jns.1996.85.1.0073

[12] Varlotto, J.M., Flickinger, J.C., Kondziolka, D., Lunsford, L.D. and Deutsch, M. (2002) External Beam Irradiation of Craniopharyngiomas: Long-Term Analysis of Tumor Control and Morbidity. International Journal of Radiation Oncology, Biology, Physics, 54, 492-499. https://doi.org/10.1016/S0360-3016(02)02965-6 
[13] Fahlbusch, R., Honegger, J., Paulus, W., Huk, W. and Buchfelder, M. (1999) Surgical Treatment of Craniopharyngiomas: Experience with 168 Patients. Journal of Neurosurgery, 90, 237-250. https://doi.org/10.3171/jns.1999.90.2.0237

[14] Couldwell, W.T., Weiss, M.H., Rabb, C., Liu, J.K., Apfelbaum, R.I. and Fukushima, T. (2004) Variations on the Standard Transsphenoidal Approach to the Sellar Region, with Emphasis on the Extended Approaches and Parasellar Approaches: Surgical Experience in 105 Cases. Neurosurgery, 55, 539-550. https://doi.org/10.1227/01.NEU.0000134287.19377.A2

[15] Adamson, T.E., Wiestler, O.D., Kleihues, P. and Yasargil, M.G. (1990) Correlation of Clinical Land Pathological Features in Surgically Treated Craniopharyngiomas. Journal of Neurosurgery, 73, 12-17. https://doi.org/10.3171/jns.1990.73.1.0012

[16] Shi, X., Wu, B., Zhou, Z., Fan, T. and Zhang, Y. (2006) Microsurgical Treatment of Craniopharyngiomas: Report of 284 Patients. Clinical Medicine Journal (Engl.), 119, 1653-1663. https://doi.org/10.1097/00029330-200610010-00010 